\title{
Conhecimento do formador de professores de Matemática que é investigador da docência
}

\section{Knowledge of the Mathematics teacher educator who being a researcher of teaching}

\author{
Flávia Cristina Figueiredo Coura ${ }^{1}$
}

Cármen Lúcia Brancaglion Passos ${ }^{2}$

\begin{abstract}
Resumo
Neste trabalho, o objetivo é compreender o conhecimento do formador de professores de Matemática que é investigador da docência e toma a docência e a formação de professores como objeto de estudo. A pesquisa se configura como um estudo de caso de caráter qualitativo, em que, pela análise de uma narrativa de experiências de desenvolvimento profissional, buscou-se identificar o conhecimento de uma docente do ensino superior para atuar na formação de professores de Matemática. Os resultados denotam que o conhecimento do conteúdo da formação inclui subdomínios do conhecimento especializado para o ensino do professor de Matemática e que ser formador exige um tipo especializado de conhecimento, voltado para o aspecto pedagógico do conteúdo da formação do professor de Matemática.
\end{abstract}

Palavras-chave: Formador de professores de Matemática; Conhecimento do formador; MTSK; Narrativa.

\begin{abstract}
In this work, the objective is to understand the knowledge of the Mathematics teacher educator who is a researcher of teaching and takes teaching and teacher education as an object of study. The research is configured as a qualitative case study, in which, through the analysis of a narrative of professional development experiences, we tried to identify the knowledge of a higher education teacher to work in the training of Mathematics teachers. The results show that the content knowledge of training includes subdomains of Mathematics Teachers' Specialized Knowledge, and that being a trainer requires a specialized type of knowledge, focused on the pedagogical aspect of the content of Mathematics teacher training.
\end{abstract}

Keywords: Mathematics teacher educators; Teacher educator's knowledge; MTSK; Narrative.

\section{Introdução}

A pesquisa sobre o formador é frequentemente citada por ser em reduzido número (European Comission, 2013), especialmente se comparada à pesquisa sobre o professor (Smith \& Flores, 2019). Somente a partir do novo milênio desponta um crescente interesse em constituir um corpo de conhecimentos a respeito do formador (Kelchtermans, Smith \& Vanderlinde, 2018), o que se reverteu em estudos que tomam como foco de investigação o docente que atua na formação de professores.

Submetido em: 30/10/2020 - Aceito em: 06/04/2021 - Publicado em: 27/05/21

${ }^{1}$ Doutora em Educação pela Universidade Federal de São Carlos. Professora da Universidade Federal de São João del-Rei, Brasil. Email: flaviacoura@ufsj.edu.br. ORCID: https://orcid.org/0000-0002-0219-1029

${ }^{2}$ Doutora em Educação pela Universidade Estadual de Campinas. Professora da Universidade Federal de São Carlos, Brasil. Email: carmenpassos@gmail.com. ORCID: https://orcid.org/0000-0002-5501-3584 
DOI: $10.20396 /$ zet.v29i00.8661842

Observamos cenário similar no que se refere ao formador de professores de Matemática (FPM). Como identificamos em Coura e Passos (2017), as 11 teses e as 19 dissertações analisadas representam 3,5\% da produção considerada em mapeamento nacional de pesquisas sobre o professor que ensina Matemática, produzidas de 2001 a 2012 (Fiorentini, Passos \& Lima, 2016). Quanto ao período de produção, os estudos também se inserem no movimento mencionado, pois a busca por relatórios de investigações realizadas em programas brasileiros de pós-graduação stricto sensu das áreas de Educação e de Ensino até o ano de 2015, feita em Coura (2018), somou somente mais um estudo (Gonçalves, 2000) aos 30 anteriormente identificados. Desse modo, além de serem em reduzido número, os estudos brasileiros sobre o formador de professor de Matemática foram realizados a partir do início do novo milênio, o que também ocorre em nível internacional (Contreras, Montes, Muñoz-Catalán \& Joglar, 2017).

É nesse movimento que se insere o estudo aqui exposto, em que procuramos apresentar uma compreensão do conhecimento especializado desse formador específico neste texto, o docente do Ensino Superior que atua na formação de professores de Matemática (PM). Entre esses, voltamos o olhar para os formadores ${ }^{3}$ que qualificamos em Coura (2018) como investigadores da docência, por tomarem como objetos de suas investigações, além de seu campo de atuação profissional, também a docência e a formação de professores.

Embora sejam um contingente minoritário em relação aos demais, entendemos que essas investigações podem fornecer elementos para compreender o conhecimento especializado desse formador em uma perspectiva que avance em relação aos estudos já produzidos, pois ele concentra sua atuação profissional no ensino de segunda ordem (Murray \& Male, 2005), ou seja, em ensinar sobre o ensino, tal como destacamos em Coura e Passos (2018). Com este estudo, podemos oferecer contribuições para a questão em aberto, indicada por Rediske de Almeida e Ribeiro (2019, p. 146), sobre "se e como o PCK [conhecimento pedagógico do conteúdo] de um formador que é matemático se diferencia do PCK de um formador com outro perfil", assim como para a pergunta que Contreras et al. (2017) fazem sobre que tipologias podem caracterizar o conhecimento especializado de um formador de professor de Matemática.

A análise da narrativa de experiências de desenvolvimento profissional de uma das participantes do estudo apresentado em Coura (2018), possibilitou-nos compreender o conhecimento especializado desse formador. Para isso, discutiremos o seu conhecimento segundo nossa leitura do modelo proposto por Carrilo, Montes, Codes, Contreras e Climent (2019). Em seguida, exporemos os aspectos metodológicos segundo os quais realizamos o estudo. Apresentaremos os resultados na narrativa analisada, quando identificarmos os tipos de conhecimento especializado do formador aqui em estudo. Ao final, discutiremos

\footnotetext{
${ }^{3}$ Embora as formadoras participantes sejam mulheres, como a questão do gênero não nos serviu de parâmetro, em algumas partes do texto mantivemos a palavra formadores para designar um grupo de profissionais dos gêneros feminino e masculino.
} 
DOI: $10.20396 /$ zet.v29i00.8661842

brevemente sobre a especificidade dos conhecimentos identificados, inclusive na perspectiva de diferenciá-los do conhecimento específico do professor de Matemática.

\section{O conhecimento do formador de professores de Matemática}

Como agentes na formação de professores, os formadores podem ser tomados como figuras-chave no desempenho profissional dos docentes e, assim, ocupariam lugar estratégico no cenário da política educativa atual, pois estão envolvidos na relação que atualmente se estabelece entre a qualidade da educação escolar e a formação do professor (Vanassche \& Kelchtermans, 2014). Assim, atuar na formação de professores exige que o formador promova um conjunto de ações que requerem dele uma compreensão complexa do ensino e da aprendizagem para fundamentar seus programas de preparação de professores (Korthagen, Loughran \& Lunenberg, 2005).

Com efeito, não basta ao formador conhecer os conteúdos, também é preciso auxiliar os professores a aprender a ensinar (Cochran-Smith, 2005). Isso quer dizer que os estudantes da Licenciatura em Matemática necessitam de suporte para transformar seus conhecimentos de conteúdo específico em conhecimentos que possam ser apreendidos pelos alunos que têm ou terão na escola. Por esse motivo, é complexo definir uma base de conhecimento dos formadores - inclusive os da formação de professor de Matemática -, pois envolve um caráter duplo: o conhecimento necessário para ensinar os alunos de seus alunos, futuros professores, e o conhecimento referente à formação de professores (Dal-Forno \& Reali, 2009).

Contudo, se a investigação sobre a formação do professor já rompeu - como em Shulman (1986), por exemplo -, a barreira de julgar suficiente, para que os alunos aprendam, que se saiba o conteúdo a ensinar, o mesmo não aconteceu em relação aos formadores. Tal como Vaillant (2003, p. 28) destacou, ainda se mantém a "crença de que o único conhecimento que se requer para ensinar é o conhecimento do que se ensina - o conteúdo ou matéria a ser ensinado". Há alguma mudança a partir do começo deste milênio (Kelchtermans et al., 2018), com a crescente defesa de que um conjunto de conhecimentos é necessário à atividade profissional do formador e, portanto, esses conhecimentos são também específicos desses profissionais (Koster, Brekelmans, Korthagen \& Wubbels, 2005).

Beswick e Goos (2018), referindo-se à formação do professor de Matemática, argumentam que, assim como foi importante compreender e articular o conhecimento específico dos professores dessa componente curricular, atualmente é preciso se concentrar no que os formadores desses docentes precisam saber e na forma como esse conhecimento é distinto daquele de professores e de outros formadores, incluindo os matemáticos.

Nesse sentido, alguns estudos (Contreras et al., 2017; Rediske de Almeida \& Ribeiro, 2019) adotam perspectivas que emergem do Mathematics Teachers' Specialized Knowledge 4

\footnotetext{
${ }^{4}$ Conhecimento especializado do professor de Matemática
} 
$(\mathrm{MTSK})^{5}$ (Carrillo et al., 2018), para analisar o conhecimento do formador do professor de Matemática. Assim também o fizeram Carrilo et al. (2019), na sua reflexão sobre o conhecimento desse profissional, a qual tomamos como referencial teórico para a análise aqui exposta.

\section{O conhecimento do conteúdo da formação}

Com efeito, Carrillo et al. (2019) defendem que o conteúdo da formação dos professores de Matemática não se limita ao conhecimento matemático. Fundamentados em Ponte (2012), entendem que tal conteúdo é composto por três grandes domínios nos quais um docente deve se desenvolver: conhecimento, identidade e habilidades profissionais. Desse modo, o conhecimento do conteúdo do formador de professores de Matemática, que se vincula à formação desses docentes certamente inclui o conhecimento matemático, mas não se limita a ele, pois é composto tanto pelo conhecimento matemático como pelo conhecimento pedagógico do conteúdo matemático que ele pretende que seus estudantes - os futuros professores de matemática - constituam. Respaldados em Zopf (2010), Carrillo et al. (2019) afirmam que o conhecimento matemático do formador deve ser mais amplo e mais profundo que o do professor, contemplando

as conexões entre diferentes aspectos do conteúdo, vinculado ao conhecimento da estrutura da Matemática, assim como em seu conhecimento da sintaxe matemática. Assim, um formador deveria ser consciente de como as diferentes propriedades dos conceitos se inter-relacionam, articulando-se com os processos de construção de novo conhecimento matemático dando a ele uma visão holística do conteúdo matemático (Carrillo et al., 2019, p. 331, tradução nossa).

Embora o conhecimento matemático do formador tenha similaridades com o Mathematical Knowledge (MK) do professor de Matemática, ele se caracteriza, em seus três subdomínios, por uma maior densidade das conexões e pela profundidade desse conhecimento. Assim, transcende o que se espera que um professor em formação aprenda (Carrillo et al., 2019).

Em se tratando do conhecimento pedagógico do conteúdo matemático (PCK), esses pesquisadores indicam que um formador deve estar familiarizado com os elementos do conhecimento do ensino de Matemática (KMT), das características da aprendizagem matemática (KFLM) e dos padrões de aprendizagem da Matemática (KMLS), nomeadamente os três domínios que compõem o PCK do professor de Matemática, conforme Carrillo et al.

\footnotetext{
${ }^{5}$ O MTSK é um modelo dedicado ao conhecimento que os professores têm da matemática como objeto de ensino e aprendizagem. Conforme Carrillo et al. (2018), é dividido em dois domínios: Conhecimento Matemático (Mathematical Knowledge - MK) e Conhecimento Pedagógico do Conteúdo (Pedagogical Content Knowledge - PCK), sendo cada um organizado em três subdomínios. O MK é composto por: Conhecimento sobre os tópicos (Knowledge of topics - KoT), Conhecimento da estrutura da Matemática (Knowledge of the structure of mathematics - KSM) e Conhecimento da prática em Matemática (Knowledge of practices in mathematics - KPM). O PCK é dividido em Conhecimento do ensino de Matemática (Knowledge of mathematics teaching - KMT), Conhecimento das características da aprendizagem da Matemática (Knowledge of features of learning mathematics - KFLM) e Conhecimento dos padrões de aprendizagem em Matemática Knowledge of mathematics learning standards (KMLS).
} 
DOI: $10.20396 /$ zet.v29i00.8661842

(2018). Dito de outro modo, argumentam que o PCK do professor deve fazer parte do conhecimento do conteúdo da formação de professores de Matemática, ou seja, o formador precisa entender os conhecimentos relativos ao ensino dos conteúdos matemáticos que almeja ajudar os futuros professores a constituir.

Os pesquisadores defendem também que o formador de professor de Matemática deve saber sobre as diferentes habilidades profissionais que um professor - de qualquer componente curricular - deve desenvolver em sua formação, tais como: a aprendizagem dos alunos na escola, o planejamento das aulas ou a concepção de ferramentas de avaliação.

Em suma, para esses autores, o conhecimento do conteúdo desse formador refere-se ao conteúdo da formação de professores, e consideramos que inclui o conhecimento especializado do professor de Matemática (MTSK) (Carrillo et al., 2018), porém o extrapola, no que se refere tanto às conexões que o formador deve estabelecer entre os diferentes aspectos do conteúdo matemático quanto à profundidade desse conhecimento e, ainda, às habilidades vinculadas ao exercício profissional do docente.

\section{O conhecimento pedagógico do conteúdo da formação}

Ao entenderem que o conteúdo da formação de professores é composto pelo conhecimento, pela identidade e pelas habilidades profissionais, Carrilo et al. (2019, p. 330, tradução nossa) asseguram que o conhecimento pedagógico do conteúdo da formação é aquele que "permitirá ao formador transformar o conteúdo da formação anteriormente descrito, em uma forma mais acessível para seus estudantes".

Entretanto, não seria uma réplica do PCK do professor, embora os autores o tomem como referência para organizar o PCK do formador, tendo como base o conhecimento deste sobre ensino, aprendizagem e currículo da formação de professores, em: conhecimento do ensino do conteúdo da formação, conhecimento das características do desenvolvimento profissional do PM e conhecimento dos padrões de formação de professores.

O conhecimento do ensino do conteúdo da formação é o que o formador de professores de Matemática possui de como organizar a formação e abarca teorias e enfoques dessa formação, incluindo dinâmicas e tarefas que permitam desenhar cenários formativos para os futuros professores de Matemática. O conhecimento que o formador tem das características do desenvolvimento profissional dos professores inclui saber como se constroem o conhecimento e a identidade profissional e também os diferentes graus de evolução das habilidades profissionais. Por último, o conhecimento dos padrões de formação de professores vincula-se mais diretamente ao nível educativo em que os professores em formação atuarão, embora deva incluir ainda uma visão mais global, que abranja os outros níveis. Esse conhecimento também contempla a capacidade de estabelecer, justificar e avaliar as metas de aprendizagem dos futuros professores e, nesse sentido, envolve também o currículo de formação de professores.

Para os autores, o PCK do formador pode ter múltiplas fontes, que contemplam a própria experiência, as leituras que fizeram sobre o desenvolvimento profissional do 
professor e sobre as discussões que empreendem com outros formadores de professores. Conjecturamos que outra fonte do PCK do formador do professor de Matemática pode ser a pesquisa que ele, formador, realiza ao longo de sua trajetória profissional, tomando a docência e a formação de professores como objeto de estudo, como procuraremos mostrar na discussão dos resultados.

\section{Aspectos metodológicos}

$\mathrm{Na}$ investigação apresentada, buscamos compreender o conhecimento de formadores de professores de Matemática que são investigadores da docência, a fim contribuir com uma resposta para a questão da especificidade do seu conhecimento. Para tanto, realizamos uma pesquisa do tipo estudo de caso de caráter qualitativo (Stake, 2009), com a perspectiva de compreender a experiência humana por meio da interpretação em uma perspectiva instrumental, ou seja, a partir de uma situação particular - o caso de uma investigadora da docência -, conhecer melhor um fenômeno de espectro mais amplo: o conhecimento especializado do formador de professores de Matemática (Alves-Mazzotti, 2006).

O material analisado é uma narrativa de experiências de desenvolvimento profissional, produzida a partir de uma entrevista dialógica em profundidade, com caráter biográfico-narrativo (Domingo Segovia, 2014), que registra parte da história de vida e de formação de Adair Mendes Nacarato - uma formadora de professores de Matemática que entendemos ser uma investigadora da docência, com mais de 30 anos de atuação e de pesquisa nessa formação específica. Produzida como recomendam Clandinin e Connelly (2011), a narrativa apresentada é uma sequência temporal de experiências que identificamos na fala da formadora e foi composta preservando sua voz proferida na entrevista e em sua própria produção acadêmica ${ }^{6}$ O texto transcrito na próxima seção refere-se ao período que inicia com o ingresso na profissão docente até sua atuação como orientadora de pesquisas com o professor que ensina Matemática. Em vista do recurso à produção bibliográfica da formadora, fizemos referência a ela de dois modos: ora pelo primeiro nome, ao reportar o que revelou na entrevista, registrado em itálico; ora segundo as normas técnicas para citação de documentos, quando nos referimos à sua fala, presente em sua obra.

Essa narrativa expressa o modo como Adair elaborou outras formas de estar na formação de professores, as quais lhe proporcionam produzir conhecimentos que fundamentam e orientam suas ações e suas práticas como formadora. Para identificar os tipos de conhecimento revelados, analisamos a narrativa de uma forma também chamada de "análise paradigmática de narrativas" (Bolívar, 2002): o texto foi examinado com apoio nas reflexões de Carrillo et al. (2019) sobre o conhecimento do formador de professor de Matemática, a fim de associar o conteúdo da narração a categorias pré-estabelecidas.

\footnotetext{
${ }^{6} \mathrm{O}$ recurso à produção acadêmica da formadora e os pressupostos que orientam a pesquisa narrativa tornaram necessária a identificação da participante, que aprovou a narrativa apresentada em Coura (2018) e concordou em ser identificada na pesquisa, que foi autorizada pelo Comitê de ética na pesquisa da UFSCar.
} 
DOI: $10.20396 /$ zet.v29i00.8661842

Ao longo da narrativa apresentada a seguir, registramos entre colchetes o tipo do conhecimento revelado em um parágrafo ou em parte dele que, nesse caso, é destacada em negrito. Usamos as siglas em inglês dos seis subdomínios do MTSK que, conforme seção anterior, compõem o conhecimento do formador de professor de Matemática no que se refere ao conhecimento do conteúdo da formação. Quanto ao conhecimento pedagógico do conteúdo da formação, indicamos os três subdomínios por extenso, uma vez que no referencial utilizado (Carrillo et al., 2019) não há siglas para designá-los. Posteriormente, na parte em que registramos nossas considerações sobre o conhecimento especializado de Adair como formadora de professores de Matemática, organizamos o conteúdo desse conhecimento, conforme o subdomínio a que se refere.

\section{Narrativa de experiências de desenvolvimento profissional de Adair Mendes Nacarato}

Adair é Licenciada em Matemática pela Pontifícia Universidade Católica de Campinas (PUC-Camp) em 1975, começou a atuar como professora de Matemática da Rede Estadual de São Paulo em 1977, onde permaneceu até a década de 1990, inclusive como docente no Centro Específico de Formação e Aperfeiçoamento do Magistério (CEFAM). Também foi professora e coordenadora de Matemática em escolas particulares de Campinas. De 1991 a 1994, cursou o mestrado em Educação na Universidade Estadual de Campinas (Unicamp) e apresentou dissertação sobre a construção do conceito de número na educação escolarizada. Entre 1996 e 2000, fez o doutorado, também no Programa de Pós-Graduação em Educação da Unicamp, quando defendeu a tese intitulada "A educação continuada sob a perspectiva da pesquisa-ação: currículo em ação de um grupo de professoras ao aprender ensinando geometria”. Desde 1999, é docente da Universidade São Francisco (USF), em Itatiba, interior de São Paulo, onde passou a integrar o Programa de Pós-Graduação em Educação a partir de 2001. Compôs a coordenação do GT7 (Grupo de Trabalho): "Formação de professores que ensinam Matemática", da Sociedade Brasileira de Educação Matemática (Sbem), por duas gestões, de 2001 a 2006.

De professora de Matemática a investigadora da docência: "eu me torno formadora de professor como professora"

Em 1977, Adair iniciou sua atividade como professora de Matemática, em uma escola da rede estadual de ensino de São Paulo, situada na periferia de Campinas. Durante esse primeiro ano de magistério, trabalhou somente nessa escola, o que foi "um aprendizado". Para ela, assim como para qualquer professor, o primeiro ano na profissão foi marcante (Nacarato, 1995, 2000a):

Além da dificuldade inicial de relacionamento com uma sala de aula, o que mais me marcou era a dificuldade dos alunos diante da Matemática. Não conseguiram resolver, com sucesso, as quatro operações com Números Naturais. E eu sabia ensinar? Não! No curso de Licenciatura estudei uma série de disciplinas teóricas mas nenhuma que discutisse as questões curriculares e pedagógicas do Ensino fundamental. Alguns 
DOI: $10.20396 /$ zet.v29i00.8661842

conteúdos eu até sabia, pelo menos teoricamente, mas as operações com Números Naturais? Isso era conteúdo de $1^{\mathrm{a}}$ a $4^{\mathrm{a}}$ série, pensava eu na época. (Nacarato, 2000a, p. 93) [Conhecimento das características do desenvolvimento profissional do PM]

Em busca de soluções para dificuldades como a mencionada, Adair passou a usar outro livro didático e outros materiais, como os kits do Programa de Expansão e Melhoria do Ensino Médio (PREMEN ${ }^{7}$ ) distribuídos pelo Instituto de Matemática, Estatística e Computação Científica (IMEC) da Unicamp. Usava os kits de geometria também nas aulas da escola particular em que começou a trabalhar em 1978, o Colégio Progresso.

Para ela, o trabalho nessa escola foi fundamental para repensar o ensino, na medida em que passou a fazer parte de um grupo que, semanalmente, discutia questões ligadas ao ensino, o que a impulsionou a buscar novas formas de trabalhar a Matemática [KMT] e, em consequência disso, a assumir a produção do próprio material didático como postura pedagógica, mesmo que no princípio esse processo de criação tenha se restringido a adaptações de materiais existentes (Nacarato, 1995). [KMT]

Como professora de Matemática, Adair atuava em outros espaços, além da sala de aula. A partir da década de 1980, se envolveu com as discussões sobre a proposta curricular do Estado de São Paulo para o Ensino Fundamental, o que a levou a trabalhar como monitora dos grupos de discussão do currículo com os professores dessa rede. Para ela, essa foi "uma fase de aquisição de muito conhecimento teórico e metodológico para o ensino de Matemática de $5^{\mathrm{a}}$ a $8^{\mathrm{a}}$ série" (Nacarato, 2000a, p. 94).

Adair conciliou o trabalho nas duas escolas até 1984, quando pediu demissão da instituição particular. Trabalhou somente na escola pública, de 1985 a 1987. Em meados de 1987, foi convidada para ser coordenadora da área de matemática do Ensino Fundamental no Colégio Rio Branco, outra escola particular de Campinas.

Ao chegar a esse ponto da narrativa de sua história, Adair interrompeu a ordem cronológica de sua fala com uma questão: "Que matemática eu sabia para ser coordenadora de todo o fundamental?". Com isso, fez referência à dúvida suscitada por esse convite - "A minha atitude inicial foi de recusa pois não tinha experiência alguma com ensino de $1^{\mathrm{a}}$ a $4^{\mathrm{a}}$ série" (Nacarato, 2000a, p. 96-97) - que, apesar disso, aceitou.

Eu falei: "Eu assumo com uma condição. Eu não sei nada dos anos iniciais. Se vocês aceitarem que eu fique esse segundo semestre acompanhando o trabalho dos professores, ouvindo, conhecendo e eu vou estudar. $O$ ano que vem, eu assumo efetivamente como coordenadora". O Fundamental II era tranquilo. E a escola topou. E aí, eu me debrucei. Estudei todos os AMs [Atividades Matemáticas], estudei tudo que a CENP produzia. [...] A CENP era a Coordenadoria de Estudos e Normas Pedagógicas, que foi um órgão fantástico junto à Secretaria de Educação do estado de São Paulo [...] Eu lia tudo que a CENP produzia. Era o auge do construtivismo. Então, a matemática, quem que você tinha? A Constance Kamii. Eu li tudo da Constance Kamii e de outros piagetianos da época. [O] livro didático do grupo da

\footnotetext{
${ }^{7}$ Instituído pelo Decreto ${ }^{\circ}$ 63.914, de 26 de dezembro de 1968, foi instituído o Programa de Expansão e Melhoria do Ensino Médio.
} 
Manhúcia, o Grupo Solução ${ }^{8}$, eles começam, então, a criar outro material voltado aos anos iniciais. E era um material fantástico. Muito do que a gente faz hoje, já estava lá no livro da Manhúcia dos anos 80. [KFLM]

Em 1988, começou a atuar como coordenadora de área de Matemática e, sob influência desses materiais, "concebidos sob pressupostos construtivistas, o que refletia as tendências da época" (Nacarato, 2000a, p. 97), constituiu suas concepções sobre ensinar e aprender Matemática - "Provavelmente o fato de eu examinar e estudar esses materiais, com tanto afinco, foi determinante na configuração de minha concepção de ensino/aprendizagem de Matemática, que, orientaria, nos anos posteriores, minha atuação profissional" [KFLM] (Nacarato, 2000a, p. 98) - e orientou seu trabalho com os docentes do Colégio Rio Branco.

Complementar a teoria com a prática dos professores foi o que lhe possibilitou entender "a importância de um trabalho com compreensão em Matemática nas séries iniciais e a importância do Sistema de Numeração Decimal, construído com significado, como alicerce para toda a Aritmética" [KMT] (Nacarato, 1995, p. 4). Isso representou uma resposta para dúvidas e inquietações que trazia consigo desde o primeiro ano de magistério: "Acredito que, com a contagem consolidada e o conceito de número construído com significado, tornar-se-á mais fácil a construção, com significado, do sistema de numeração decimal" (Nacarato, 2000b, p. 105). [KMT]

Em relação a esse período, afirmou: "Começo, então, a trabalhar como coordenadora de área de matemática. E foi ai que eu fui aprender matemática dos anos iniciais”. Como registrou em Nacarato (2000a), foi um período de busca e de produção de conhecimento sobre as situações de ensino-aprendizagem nas séries iniciais do Ensino Fundamental, que a fez refletir e mudar sua prática como professora nos anos finais. Segundo ela: "sem dúvida alguma, esse foi um período que contribuiu para o meu desenvolvimento profissional" (Nacarato, 2000a, p. 98).

Esse percurso a fez compreender que "o domínio do conteúdo específico não garante a eficiência na sala de aula" (Nacarato, 1995, p. 4) e que o

Curso de Licenciatura Plena em Matemática forneceu, sem dúvida, importantes elementos teóricos na área. No entanto, todo o meu conhecimento como professora de Matemática de Ensino Fundamental foi construído com base na minha vivência em sala de aula, minhas angústias diante das dificuldades dos alunos em compreender determinados tópicos da matéria e, principalmente, pela minha busca constante de soluções aos desafios que me eram colocados. (Nacarato, 2000a, p. 92) [Conhecimento das características do desenvolvimento profissional do PM]

Adair se colocou pela primeira vez como formadora de professores quando se referiu a esse período em que atuou como coordenadora da área de Matemática, de meados de 1987 ao final de 1990, no Colégio Rio Branco - “E, até então, eu era só professora. Eu não tinha

\footnotetext{
${ }^{8}$ Livro didático Fazendo e compreendendo a Matemática, de Manhúcia P. Liberman e Regina Wey, Editora Solução (Nacarato, 2000a, p. 97)
} 
nenhuma especialização. Então, eu me torno formadora de professor como professora". Sobre seu "Percurso de formadora de professores" (Nacarato, 2000a, p. 96), assinalou que:

Hoje, lançando um olhar retrospectivo sobre esse período, que foi de 1987 ao final de 1990, posso dizer que minha atuação junto a esses professores não tinha a preocupação com a preparação para a sua prática com base em teorias prontas e acabadas. Partíamos sempre da necessidade prática do grupo. Não houve imposição de nenhuma teoria norteadora, nem de material didático a ser utilizado. Tudo era feito dentro de uma negociação, tendo como principal referencial os saberes da experiência de cada uma. A minha atuação, como coordenadora e como elemento externo, era de discutir, com o grupo, exclusivamente questões da prática pedagógica, sem muita preocupação com 'teorias' - mesmo porque eu julgava não as ter ainda - mas com ênfase no dia-a-dia da sala de aula. (Nacarato, 2000a, p. 98) [Conhecimento do ensino do conteúdo da formação de PM]

Em 1991, iniciou o mestrado e voltou a ser professora de Matemática no Colégio Progresso, a primeira instituição privada de ensino em que havia trabalhado. A partir de 1993, assumiu o cargo de coordenadora da área de Matemática de $1^{\mathrm{a}}$ a $4^{\mathrm{a}}$ série nessa escola e começou a trabalhar com grupos de formação de professores de redes municipais de ensino, no interior de Minas Gerais e no estado de São Paulo.

Se não teve dificuldades para assumir novamente um cargo de coordenação - "já tinha um conhecimento construído com a primeira experiência e já tinha também um embasamento teórico que estava sendo adquirido com o Mestrado" (Nacarato, 2000a, p. 104) -, segundo Adair, o trabalho com professores da rede pública, "foi muito diferente de tudo que havia feito até então" (p. 111). Embora isso a tenha levado a "mais estudos e reflexões" (p. 111), o foco permaneceu direcionado ao que acontecia na sala de aula:

Se, de um lado, eu reconhecia a existência de um grupo de professoras, muitas delas de zona rural e algumas leigas que não possuíam conhecimento matemático mínimo para ensinar e, portanto, necessitavam de conhecimento de conteúdo, reconhecia também a necessidade da valorização da prática pedagógica dessas professoras que me era suscitada pelas leituras que fazia. Mas como conciliar tudo isso? Procurava nos poucos encontros que tínhamos - média de quatro encontros por ano, de oito horas cada um - trabalhar/discutir articuladamente aspectos teóricos e situações de sala de aula. (Nacarato, 2000a, p. 112) [Conhecimento do ensino do conteúdo da formação de PM]

Em 1994, terminou o mestrado e, no ano seguinte, começou a participar do PraPeM ${ }^{9}$, "para poder manter um vínculo com a universidade". Durante o ano de 1995, teve contato com as questões relativas ao professor reflexivo e às contestações ao paradigma da racionalidade técnica, a partir das leituras que fez dos textos de Schön.

Essas discussões teóricas me levaram a uma reflexão sobre minha própria prática. $\mathrm{E}$ isso me deixava em conflitos: como me desvencilhar do paradigma da racionalidade técnica? Ele parece ser muito forte em minha formação e em minha trajetória como formadora de professore(as)s. Como tomar a prática do(a)s professore(a)s como ponto de partida e de chegada? E a questão da teoria, como fica? Como tornar um(a) professor(a) reflexivo(a) sobre sua própria prática? Refletir a partir do quê? Uma

\footnotetext{
${ }^{9}$ PraPem: Grupo Prática Pedagógica em Matemática.
} 
DOI: $10.20396 /$ zet.v29i00.8661842

reflexão sem fundamentos teóricos? (Nacarato, 2000a, p. 118) [Conhecimento das características do desenvolvimento profissional do PM]

Adair levou essas questões consigo para o doutorado, que iniciou em 1996, quando também estudou outros construtos teóricos:

eu fui me aperfeiçoando, tendo mais noções do que seria trabalhar com formação $e$ entro, então, para fazer a pesquisa de doutorado no campo da formação. Então, era o auge. Estava chegando no Brasil o quê? Professor reflexivo do Schön, do Zeichner, do Elliott. Então, foi essa efervescência que eu fui viver durante o meu doutorado e que acabei usando muita coisa na minha tese. [Conhecimento das características do desenvolvimento profissional do PM]

Durante o doutorado, as discussões teóricas no grupo de pesquisa e o confronto com a prática originaram novos conflitos - "Como discutir o conhecimento pedagógico sem o conhecimento específico da matéria? Como discutir a valorização, por parte do(a) professor(a), de alguns temas matemáticos em detrimento de outros?" (Nacarato, 2000a, p. 120) -, tais como novas percepções - "percebi que, num processo de educação continuada, a concepção do(a) professor(a) formador(a) inevitavelmente acaba prevalecendo (Nacarato, 2000a, p. 120) - e reflexões - "passei a refletir sobre e necessidade de se considerar, num trabalho de educação continuada, as condições de trabalho docente (Nacarato, 2000a, p. 121). [Conhecimento das características do desenvolvimento profissional do PM]

Embora Adair atuasse como formadora desde 1987, quando foi coordenadora da área de Matemática no Ensino Fundamental pela primeira vez, essa trajetória contemplou prioritariamente a formação de professores em exercício. Foi a partir do ano 2000, depois que concluiu o doutorado e ingressou na Universidade São Francisco (USF), que ela passou a atuar na formação inicial de professores no Ensino Superior, como docente responsável por disciplinas como Fundamentos e Metodologia do Ensino de Matemática, no curso de Pedagogia; e Prática Pedagógica, Estágio Supervisionado, Didática, Laboratório de Ensino de Matemática e Tendências do Ensino de Matemática, na Licenciatura em Matemática.

A publicação das diretrizes para os cursos de formação de professores da Educação Básica (BRASIL, 2001a, 2001b) provocou uma reestruturação no currículo da Licenciatura em Matemática da instituição em que Adair atuava, pois realçou "a necessidade de se repensar o lugar e o papel do estágio na licenciatura, buscando uma ruptura dos pólos dicotômicos: teoria e prática e colocando ênfase no papel da pesquisa na formação inicial" (Nacarato, 2006a, p. 1) [Conhecimento dos padrões de formação de PM]. Em vista disso, ela concentrou suas atividades de ensino nas unidades curriculares com carga horária dedicada à prática pedagógica e no Estágio Supervisionado do curso de Matemática.

Envolvida que estou com estudos e pesquisas sobre e com professores que ensinam Matemática, ao assumir, no segundo semestre de 2005, a disciplina de Estágio Supervisionado com uma turma de 40 semestre do curso de Licenciatura em Matemática da USF, cujo regulamento de estágio prevê a realização de um projeto de intervenção, considerei que esse seria um campo fértil para que os futuros professores pudessem ser inseridos no campo da pesquisa. (Nacarato, 2006a, p. 4) [Conhecimento das características do desenvolvimento profissional do PM] 
A respeito desse período, em que orientou estágio supervisionado na Licenciatura em Matemática, disse que

foi quando, então, eu fui conhecer o que é estágio. E a gente já fazia alguma coisa bem diferente na época, trabalhava com projeto de intervenção. Então, os alunos iam para a observação, diagnosticavam o problema junto com o professor, o professor dava a dica. Às vezes, era até aula de reforço que o professor pedia. Mas a gente montava, e sempre na forma de projeto, sempre pensando já na ideia da pesquisa como eixo da formação do professor. [Conhecimento do ensino do conteúdo da formação de PM]

Para Adair, a realização de projetos de intervenção no estágio é uma estratégia formadora e um campo fértil para que os futuros professores possam ser inseridos no campo da pesquisa, pois permite aos licenciandos compreender a prática e problematizar as situações que observam e envolve um movimento de definir temáticas, escolher referenciais teóricos, analisar e selecionar situações para a regência (Nacarato, 2006a). [Conhecimento do ensino do conteúdo da formação de PM]

A preocupação constante, como formadora de professores, com a produção de um repertório de saberes docentes (Nacarato, Grando, Toricelli \& Tomazetto, 2008) também a levou a implementar uma proposta, junto com a professora Regina Célia Grando ${ }^{10}$, que tivesse o cuidado de resgatar conteúdos matemáticos da Educação Básica, pois sua experiência na Licenciatura em Matemática vinha indicando que, a cada ano, os alunos ingressam no Ensino Superior com mais defasagem de conteúdos básicos da etapa de escolarização anterior (Nacarato, 2006b).

O que é que a gente sabe? Que o aluno chega para fazer licenciatura e não sabe nada de Geometria. Então... E como é que ele vai ser professor de Geometria? Nós criamos a chamada Oficina de Geometria, que era na pré-aula deles, das cinco às sete. Sete e quinze começava a aula [na graduação]. [Conhecimento das características do desenvolvimento profissional do $\mathbf{P M ]} E$ aí, a gente teve a grande sacada de chamar professor para participar. Então, essa oficina é que virou o GRUCOMAT, que existe desde 2003, quando nós criamos as famosas oficinas de geometria. Então, a gente ficou anos com geometria, depois, a gente foi mudando. Cada período, o GRUCOMAT vai, então, criando projetos de pesquisa.

De acordo com Nacarato, Grando e Eloy (2009), a constituição desse grupo pautou-se em pressupostos teóricos que orientavam a concepção de formação docente das formadoras: tomar as contribuições de grupos de dimensões colaborativas e a adoção de estratégias formativas como elementos potencializadores da aprendizagem docente [Conhecimento das características do desenvolvimento profissional do PM]. No grupo, composto pelas duas formadoras, alunos da Licenciatura em Matemática da USF e professores de Matemática, o processo formativo adotado envolvia e ainda envolve elaboração, aplicação, análise e sistematização de atividades em sala de aula da escola básica. Os autores consideraram que, com essa dinâmica, os professores da escola ampliavam seus saberes docentes sobre Geometria, os licenciandos começavam a construir saberes sobre a docência e as

${ }^{10}$ Profa. Dra. Regina Célia Grando (http://lattes.cnpq.br/6878232320203358) 
formadoras construíram uma metodologia de formação docente. [Conhecimento do ensino do conteúdo da formação de PM]

Como formadora de professores, Adair tem tomado sua experiência como objeto de reflexão e pesquisa, buscando sistematizar algumas práticas de formação que tem priorizado (Nacarato, 2010, p. 906). Com isso, constituiu princípios que têm orientado sua atuação:

Temos defendido que o saber profissional do professor se constitui na e a partir da prática pedagógica. É a partir da problematização da prática que o professor passa a refletir e produzir significados para os acontecimentos que vivencia. Os saberes específicos do conteúdo - muitas vezes adquiridos nos cursos de licenciatura - sofrem (re)significações quando trabalhados em sala de aula, pois passam a ser imbricados com as questões pedagógicas e curriculares. Constituem, assim, uma unidade em que não é mais possível separar o conteúdo específico, do pedagógico e do curricular.

Defendemos ainda que os contextos que privilegiam a problematização, análise e reflexão da prática pedagógica são potencializadores do desenvolvimento profissional docente. (Nacarato et al., 2008, p. 200) [Conhecimento das características do desenvolvimento profissional do PM]

Para Adair, a produção de conhecimento por parte dos professores pode se desenvolver quando eles assumem uma postura investigativa, resultando em conhecimento $d a$ prática (Cochran-Smith \& Lytle, 1999). Nessa perspectiva, ela entende que, na parceria universidade escola,

os professores da universidade aprendem e investigam com os professores da escola básica, reconhecendo-os como protagonistas da própria prática e do desenvolvimento curricular; e estes, por sua vez, podem se tornar consumidores críticos das teorias produzidas pelas pesquisas acadêmicas e, também, constituir-se pesquisadores no cotidiano escolar - podem, ao mesmo tempo, produzir conhecimentos e fazer da investigação uma ferramenta da sua prática docente. (Nacarato, Grando \& Mascia, 2013, p. 27) [Conhecimento das características do desenvolvimento profissional do PM]

Tecer suas pesquisas com as dos professores reais e em suas reais condições de trabalho, dando visibilidade e legitimidade às investigações que eles realizam em suas salas de aula (Nacarato; Grando, 2015), tem representado para Adair outra forma de manter contato com escola, algo que ela entende como fundamental para ser formador.

Para ser formador, não basta ser um bom professor. Lógico que ser um bom professor ajuda. Mas eu acho que o formador precisa algo mais. Ele precisa conhecer a realidade da escola. Então a gente que já se afastou, que está na universidade, você conhece o cotidiano da escola? Não conheço. Mas se eu ouço o professor, eu conheço. Indiretamente, eu conheço. Se eu produzo um vídeo da escola, como o nosso grupo costuma produzir, eu passo a ver o que é uma escola, como é que está uma sala de aula. [...] Então, para mim, hoje, é tudo muito distante. Então, para mim, a escola é a escola que os professores narram. Então, é essa escola que eu conheço. Eu não estou mais lá na sala de aula. [Conhecimento dos padrões de formação de PM]

Em sua trajetória como formadora de professores, tem se dedicado a evidenciar a importância de uma prática docente pautada na reflexão, na sistematização das produções das alunas do curso de Pedagogia (Nacarato, 2010), dos estudantes da Licenciatura em Matemática, dos professores da Educação Básica e no movimento de escutar o que esses 
docentes em formação têm a dizer: sobre si mesmos, sua trajetória de formação e suas aprendizagens. Assim como registrou: "a possibilidade de olhar para essas produções e poder analisá-las e refletir sobre a minha própria prática, sistematizando algumas dessas reflexões (como neste artigo), é fundamental para minha constituição profissional” (Nacarato, 2010, p. 927).

\section{Considerações sobre o conhecimento especializado de Adair como FPM}

Adair se insere no grupo de formadores de professor de Matemática que se moveram do ensino de primeira ordem, cujo objeto era a matemática na Educação Básica, para o de segunda ordem, ou seja, passaram a ensinar sobre o ensino (Murray \& Male, 2005). Ela começou a atuar como formadora de professores de Matemática, sem preparação formal para exercer esse papel, enquanto lecionava Matemática na Educação Básica. Na condição de formadora iniciante, atuou prioritariamente em sua área de especificidade - a Matemática -, fundamentada em um conhecimento gerado em grande parte na prática profissional como professora especialista (Coura \& Passos, 2018).

O conhecimento mais diretamente relacionado à atuação como professora de Matemática se mostra no início da narrativa, predominantemente composto por dois subdomínios do PCK do PM: o KMT e o KFLM. A busca por novas formas de trabalhar a Matemática, a necessidade de adaptar os materiais didáticos existentes e a importância que atribui ao conceito de número e ao Sistema de Numeração Decimal para a aprendizagem da Aritmética nos anos iniciais são indícios de conhecimento matemático para o ensino (KMT). Ao mencionar os pressupostos construtivistas como os que configuraram sua concepção de ensino-aprendizagem como teoria subjacente para o ensino, ela mostra indicativos de conhecimento das características da aprendizagem da Matemática (KFLM). A narrativa mostra que o conhecimento de Adair como FPM é composto por aqueles que ela almeja ajudar docentes e futuros professores a constituir, no que se refere ao ensino dos conteúdos matemáticos. Esse resultado denota que o conhecimento do conteúdo da formação como FPM inclui subdomínios do conhecimento especializado para o ensino do PM, tal como afirmam Carrillo et al. (2019).

O conhecimento pedagógico do conteúdo da formação, dimensão específica do conhecimento do FPM (Carrillo et al., 2019), é o que se faz mais presente na narrativa, com exemplos dos seus três subdomínios. Os pressupostos originados quando Adair atuava como PM a orientaram desde o início de seu trabalho como FPM e compunham uma teoria à qual recorria para fundamentar sua proposta de formação dos professores, ou seja, seu conhecimento das características do desenvolvimento profissional dos professores. $\mathrm{Na}$ narrativa, esse conhecer sobre como se constroem a identidade e o conhecimento do PM é o que mais se faz presente, manifestado em todas as vezes que Adair mostra conhecer os aspectos do desenvolvimento profissional docente, o que faz ao indicar alguns construtos teóricos que subjazem a sua atuação como FPM - influência da racionalidade técnica, relação entre teoria e prática, professor reflexivo, contribuições de grupos de dimensões 
colaborativas, constituição do saber profissional a partir da prática, postura investigativa resultando em conhecimento na prática. Esse subdomínio do conhecimento pedagógico do conteúdo da formação também é revelado quando ela menciona as dificuldades do processo de constituição dos conhecimentos específicos do PM - "Como discutir o conhecimento pedagógico sem o conhecimento específico da matéria?" -, ao indicar as formas que considera mais apropriadas para que o PM construa os conhecimentos necessários ao seu exercício profissional - "É a partir da problematização da prática que o professor passa a refletir e produzir significados para os acontecimentos que vivencia". E ainda quando considera as dificuldades que os futuros PM trazem da escolarização anterior para a Licenciatura em Matemática, o que fez quando criou a Oficina de Geometria.

O conhecimento do ensino do conteúdo da formação de PM revela-se nas diversas atividades que Adair propunha para desenvolver o conhecimento e as habilidades profissionais dos PM: partindo "sempre da necessidade prática do grupo" de professores em que atuou como formadora pela primeira vez, valorizando a prática pedagógica das professoras leigas, para "trabalhar/discutir articuladamente aspectos teóricos e situações de sala de aula" e para organizar o estágio supervisionado como projeto de intervenção, envolvendo "elaboração, aplicação, análise e sistematização de atividades em sala de aula da escola básica".

O conhecimento dos padrões de formação de professores está presente na narrativa de Adair, quando menciona as diretrizes para a formação de professores (Brasil, 2001b), contemplando também o conhecimento da escola e do currículo do nível de ensino em que os professores em formação atuam ou atuarão quando concluírem seu curso.

O conhecimento pedagógico do conteúdo da formação de PM revelado na narrativa, que Carrillo et al. (2019) associam ao PCK do formador e, tal como esses autores afirmam, extrapola o conhecimento especializado do PM, denota um conhecimento que Adair constituiu na prática de formar esses docentes: com os estudos da Educação Matemática e as pesquisas sobre a formação de professores, ela constituiu conhecimentos específicos para os objetivos e as atividades próprias de seu trabalho como formadora.

Esses resultados reforçam a existência do conhecimento especializado do FPM que, no caso de Adair, contempla especialmente os conhecimentos sobre como os professores aprendem e como se tornam competentes - PCK do formador. Embora haja similaridades entre ensinar matemática e ensinar sobre o ensino dessa disciplina, passar do ensino de primeira para o de segunda ordem exige adquirir novos tipos de conhecimento, especialmente quando se percebe que, para atuar na formação de PM, não basta transmitir conhecimento, seja ele matemático ou sobre as práticas de ensino.

\section{Agradecimentos:}

Registramos nossos agradecimentos às participantes da pesquisa de Coura (2018), que nos concederam o privilégio de ouvir e contar suas histórias de vida, especialmente, a Adair, cuja narrativa trouxemos a este texto. 
DOI: $10.20396 /$ zet.v29i00.8661842

\section{Referências}

Alves-Mazzotti, A. J. (2006). Usos e abusos dos estudos de caso. Cadernos de Pesquisa, 36(129), 637-651.

Beswick, K., \& Goos, M. (2018). Mathematics teacher educator knowledge: What do we know and where to from here? Journal of Mathematics Teacher Education, 21, 417-427. https://doi.org/10.1007/s10857-018-9416-4.

Bolívar, A. (2002). ¿De nobis ipsis silemus?: Epistemología de la investigación biográficonarrativa en educación. Revista Electrónica de Investigación Educativa, 4(1), 1-26.

Brasil. Conselho Nacional de Educação. Câmara de Educação Superior. Diretrizes Curriculares Nacionais para os Cursos de Matemática, Bacharelado e Licenciatura. Parecer CNE/CES 1.302/2001. MEC: Brasília, 2001a.

Brasil. Conselho Nacional de Educação. Diretrizes Curriculares Nacionais para a Formação de Professores da Educação Básica, em nível superior, curso de licenciatura, de graduação plena. Parecer CNE/CP 009/2001. Brasília: MEC, 2001 b.

Carrillo, J., Climent, N., Montes, M., Contreras, L. C., Flores-Medrano, E., Escudero- Ávila, D., ... Muñoz-Catalán, M.C. (2018). The Mathematics Teacher's Specialised Knowledge (MTSK) model. Research in Mathematics Education, 20(3), 236-253.

Carrillo, J., Montes, M., Codes, M., Contreras, L. C., \& Climent, N. (2019). El conocimiento didáctico del contenido del formador de professores de matemáticas: su construcción a partir del análisis del conocimiento especializado pretentido em el futuro professor. In F. Imbernón, A. S. Neto, \& I. Fortunato (Orgs.), Formação permanente de professores: experiências ibero-americanas (pp. 324-343). São Paulo: Hipótese.

Clandinin, D. J., \& Connelly, F. M. (2011). Pesquisa narrativa: experiência e história em pesquisa qualitativa (Grupo de Pesquisa Narrativa e Educação de Professores ILEEI/UFU, Trads.). Uberlândia: EDUFU.

Cochran-Smith M. (2005). Teacher educators as researchers: Multiple perspectives. Teaching and Teacher Education, 21, 219-225.

Cochran-Smith, M.; \& LYTLE, S. L. (1999). Relationships of knowledge and practice: Teacher learning in communities. Review of Research in Education, Washington, 24, 249-305.

Contreras, L. C., Montes, M., Muñoz-Catalán, M. C., \& Joglar, N. (2017). Fundamentos teóricos para conformar un modelo de conocimiento especializado del formador de profesores de matemáticas. In J. Carrillo, \& L. C. Contreras (Eds.), Avances, utilidades y retos del modelo MTSK. Actas de las III Jornadas del Seminario de Investigación de Didáctica de la Matemática de la Universidad de Huelva (pp. 11-25). Huelva: CGSE.

Coura, F. C. F. (2018). Desenvolvimento profissional de formadores de professores de Matemática que são investigadores da docência (Tese de doutorado em Educação). São Carlos: Universidade Federal de São Carlos.

Coura, F. C. F., \& Passos, C. L. B. (2017). Estado do conhecimento sobre o formador de professores de Matemática no Brasil. Zetetiké, 25(1), 7-26. 
Coura, F. C. F., \& Passos, C. L. B. (2018). De professor a formador: ensinar sobre o ensino. In L. F. Passos (Org.), Formação de formadores e cursos de Licenciatura: contextos, práticas e pesquisas (pp. 167-194). Campinas: Pontes.

Dal-Forno, J. P.; Reali, A. M. M. R. (2009). Formação de formadores: delineando um programa de desenvolvimento profissional da docência via internet. Revista Profissão Docente, 9 (20), 75-99.

Domingo Segovia, J. (2014). Teoria fundamentada del professorado desde um enfoque biográfico-narrativo. Fundamentación, processos e herramientas. In M. H. M. B. Abrahão, \& A. Botía (Orgs.), La investigación (auto)biográfica en educación: miradas cruzadas entre Brasil y España (pp. 110-141). Granada: Editorial Universidad de Granada, 2014.

European Comission. (2013). Supporting teacher educators for better learning outcomes. European Commission.

Fiorentini, D., Passos, C. L. B., \& Lima, R. C. R. (2016). Mapeamento da pesquisa acadêmica brasileira sobre o professor que ensina matemática: período 2001 - 2012. Campinas, SP: FE/UNICAMP.

Gonçalves, T. O. (2000). Formação e desenvolvimento profissional de formadores de professores: o caso dos professores de matemática da UFPA. Tese de Doutorado em Educação. Campinas: Universidade Estadual de Campinas.

Kelchtermans, G., Smith, K., \& Vanderlinde, Ruben. (2018). Towards an 'international forum for teacher educator development': an agenda for research and action, European Journal of Teacher Education, 41(1), 120-134. https://doi.org/10.1080/02619768.2017.1372743

Korthagen, F., Loughran, J., \& Lunenberg, M. L. (2005). Teaching teachers: studies into expertise of teacher educators: An introduction to this theme issue. Teaching and Teacher Education, 21(2), 107-115. https://doi.org/10.1016/j.tate.2004.12.007

Koster, B., Brekelmans, M., Korthagen, F., \& Wubbels, T. (2005). Quality requirements for teacher educators. Teaching and Teacher Education, 21(2), 157-176.

Murray, J., \& Male, T. (2005). Becoming a teacher educator: evidence from the field. Teaching and Teacher Education: An International Journal of Research and Studies, $21(2), 125-142$.

Nacarato, A. M. (1995). A construção do conceito de número na educação escolarizada. Dissertação de Mestrado em Educação. Campinas: Universidade Estadual de Campinas.

Nacarato, Adair Mendes. (2000a). Educação continuada sob a perspectiva da pesquisa ação: currículo em ação de um grupo de professoras ao aprender ensinando Geometria. Tese Doutorado em Educação. Campinas: Universidade Estadual de Campinas.

Nacarato, A. M. (2000b). O conceito de número: sua aquisição pela criança e implicações na prática pedagógica. Argumento - Revista das Faculdades de Educação, Ciências e Letras e Psicologia Padre Anchieta, 3, 84-106.

Nacarato, A. M. (2006a). O estágio na pesquisa e a pesquisa no estágio. Anais do $13^{\circ}$ Encontro Nacional de Didática e Prática de Ensino. Recife. 
DOI: 10.20396/zet.v29i00.8661842

Nacarato, A. M. (2006b). A Formação do professor de matemática: pesquisa x políticas públicas. Contexto e Educação, 75, 131-153.

Nacarato, A. M. (2010). A formação matemática das professoras das séries iniciais: a escrita de si como prática de formação. Bolema - Boletim de Educação Matemática, 23, 905930.

Nacarato, A. M., \& Grando, R. C. (2015). A pesquisa com e pelas professoras que ensinam matemática. Anais do VI Seminário Internacional de Pesquisa em Educação Matemática (pp.1-15). São Paulo: SBEM,

Nacarato, A. M., Grando, R. C., \& Eloy, T. A. (2009). Processos formativos: compartilhando aprendizagens em geometria com diferentes mídias. In D. Fiorentini, R. C. Grando, \& R.C. Miskulin, Práticas de formação e de pesquisa de professores que ensinam matemática (pp. 189-210). Campinas: Mercado de Letras.

Nacarato, A. M., Grando, R. C., \& Mascia, M. A. A. (2013). A formação docente em projetos de parceria universidade e escola. Acta Scientiae - ULBRA, (15), 24-41.

Nacarato, A. M., Grando, R. C., Toricelli, L. \& Tomazetto, M. (2008). Professores e futuros professores compartilhando aprendizagens: dimensões colaborativas em processo de formação. In A. M. Nacarato \& M.A.V. Paiva, A formação do professor que ensina matemática: perspectivas e pesquisas (pp. 197-212). Belo Horizonte: Autêntica.

Ponte, J.P. (2012). Mathematics teacher education programs: practice and research. Journal of Mathematics Teacher Education, 15(5), 343-346.

Rediske de Almeida, M. V., \& Ribeiro, M. (2019). Conhecimento especializado do formador de professores de Matemática ao discutir a relação de ordem no conjunto dos números inteiros. Quadrante, 28(2), 125-148. Retirado em 25 de janeiro de 2020, de https://quadrante.apm.pt/index.php/quadrante/article/view/490

Shulman, L. S. (1986). Those who understand: Knowledge growth in teaching. Educational Researcher, 15(2), 4-14. https://doi.org/10.3102/0013189X015002004

Smith, K., \& Flores, M. A. (2019). The Janus faced teacher educator. European Journal of Teacher Education, 42(4), 433-446. https://doi.org/10.3102/10.1080/02619768.2019.1646242

Stake, R. E. (2009). A arte da investigação com estudos de caso (2 ${ }^{\mathrm{a}}$ ed.). Lisboa: Fundação Calouste Gulbenkian.

Vaillant, D. (2003). Formación de formadores. Estado de la práctica. Buenos Aires: Preal.

Vanassche, E., \& Kelchtermans, G. (2014) Teacher educators' professionalism in practice: Positioning theory and personal interpretative framework. Teaching and Teacher Education, 44, 117-127.

Zopf, D. A. (2010). Mathematical knowledge for teaching teachers: The mathematical work of and knowledge entailed by teacher education. Unpublished Doctoral Dissertation. Michigan: University of Michigan. 